\title{
KORELASI KOMITMEN PEGAWAI DENGAN EFEKTIVITAS ORGANISASI PADA UNIT PELAKSANA TEKNIS DAERAH PENDAPATAN WILAYAH VII PRINGSEWU
}

\author{
Husna Purnama ${ }^{(1)^{*}}$, Nuzleha ${ }^{(2)}$, Wahyuno ${ }^{(3)}$ \\ Fakultas Ekonomi Universitas Sang Bumi Ruwa Jurai \\ *email: husnapurnama@fe.saburai.ac.id,
}

\begin{abstract}
Abstrak. Tujuan penelitian ini adalah untuk mengetahui korelasi komitmen pegawai dengan efektivitas organisasi. Hipotesis yang diajukan adalah ada hubungan komitmen pegawai dengan efektivitas organisasi. Obyek pada penelitian ini adalah pegawai pada Unit Pelaksana Teknis Daerah (UPTD) Pendapatan Wilayah VII Pringsewu. Sampel yang digunakan sebanyak 40 orang pegawai. Pengolahan data primer dengan pendekatan metode analisis kuantitatif dibantu alat statistik aplikasi program SPSS versi 21.0. untuk perhitungan uji validitas, uji reliabilitas, uji korelasi dan uji koefisien determinasi. Berdasarkan hasil penelitian diperoleh kesimpulan sebagai berikut: Tingkat korelasi antara variabel komitmen pegawai (X) dengan variabel efektivitas organisasi (Y) pada UPTD Pendapatan Wilayah VII Pringsewu adalah sebesar 0,694. Jika dikonsultasikan dengan tabel Interpretasi Koefesien Korelasi maka tingkat korelasi komitmen pegawai (X) dengan variabel efektivitas organisasi $(\mathrm{Y})$ masuk dalam kategori korelasi "tinggi". Dengan demikian dapat disimpulkan bahwa komitmen pegawai berkorelasi dengan efektivitas organisasi.
\end{abstract}

Kata Kunci : Komitmen Pegawai, Efektivitas Organisasi

\begin{abstract}
The purpose of this study was to determine employee commitment to organizational effectiveness. The hypothesis proposed is that there is a relationship between employee commitment and organizational effectiveness. The object of this research is the employee of the Regional Technical Implementation Unit (UPTD) Regional Revenue VII Pringsewu. The sample used was 40 employees. Primary data processing with quantitative analysis approach assisted by statistical tools SPSS program application version 21.0. for the calculation of the validity test, reliability test, correlation test and coefficient of determination test. Based on the results of the study as follows: The level of correlation between employee commitment $(X)$ and organizational effectiveness variable (Y) at UPTD Revenue Region VII Pringsewu is 0.694. If consulted with the Correlation Coefficient Interpretation table, the correlation level of employee commitment $(X)$ with organizational effectiveness variable $(Y)$ is included in the "high" correlation category. Thus it can be said that employee commitment is correlated with organizational effectiveness.
\end{abstract}

Keywords: Employee Commitment, Organizational Effectiveness

\section{PENDAHULUAN}

Organisasi pemerintah memerlukan adanya perubahan dan penataan, guna menyesuaikan dengan kebutuhan situasi dan kondisi sosial dinamis dewasa ini. Kondisi ini menuntut pengembangan sistem organisasi menuju penyempurnaan sistem kerja yang relevan dengan tujuan efektivitas dan efisiensi.

Efektivitas sangat berkait dengan pencapaian tujuan. Sejalan dengan tujuan pemerintahan untuk mewujudkan kemakmuran dan kesejahteraan yang berkelanjutan, sangat jelas dan nyata diperlukan langkah-langkah efisiensi dan 
efektivitas dalam penyelenggaraan pemerintahan dan pembangunan, sehingga berdaya guna yang tinggi dengan memperhatikan peluang dan tantangan global.

Efektivitas Organisasi merupakan menurut Hidayat dalam efektivitas adalah suatu ukuran yang menyatakan seberapa jauh target (kuantitas, kualitas, dan waktu) telah tercapai.

Menurut Robin dalam (Purnomo 2006) bawa efektivitas organisasi ditentukan oleh faktor-faktor antara lain : motivasi pegawai, kepemimpinan, dan disiplin pegawai. Juga dijelaskan oleh bahwa efektivitas organisasi sangat dipengaruhi oleh efektivitas kerja orang perseorangan. Oleh karenanya komitmen dalam individu juga penting.

Dalam (Noorhani menyebutkan bahwa efektivitas organisasi yang tinggi sangat diperlukan dalam setiap usaha kerja sama pegawai untuk mencapai tujuan organisasi, yang seperti kita ketahui bahwa pencapaian tujuan organisasi ini adalah sesuatu yang diidam-idamkan oleh setiap organisasi.

Efektivitas organisasi menggambarkan tercapainya pelaksanaan kerja pada kelembagaan secara baik, tepat waktu dan sesuai dengan program kerja yang telah direncanakan. Efektivitas organisasi adalah menggambarkan suatu tingkat keberhasilan suatu organisasi dalam usahanya untuk mencapai tujuan atau sasaran yang telah ditetapkan dalam satuan waktu dan rencana tertentu.

Organisasi yang baik adalah yang mampu tumbuh dan berkembang dengan menitikberatkan pada sumber daya manusia guna menjalankan fungsinya dengan optimal, khususnya menghadapi dinamika perubahan lingkungan yang terjadi. Bilamana memiliki sumber daya manusia yang andal, disamping dominasi tekhnolgi dan fasilitas kerja, oleh karena itu investasi dalam sumber daya manusia bagi sebuah organisasi merupakan suatu keharusan. Setiap lembaga mengharapkan sumber daya manusia yang ada terus menerus mampu mengambangkan dirinya secara proaktif. Sumber daya manusia harus menjadi manusia-manusia pembelajar, yaitu pribadi-pribadi yang mau belajar serta bekerja keras dengan penuh semangat sehingga potensi insaninya dapat berkembang maksimal.

Sumber daya manusia yang diperlukan saat ini adalah sumber daya manusia yang sanggup menguasai tekhnologi dengan cepat, adaptif juga responshif terhadap perubahan-perubahan teknologi. Dalam kondisi ini integitas masing-masing individu semakin penting untuk mengembangkan pribadinya menjadi pegawai yang mampu mencapai tujuan organisasi tempatnya bekerja.

Salah satu faktor yang cukup penting dalam mewujudkan tercapainya efektivitas organisasi adalah komitmen pegawai yang tinggi untuk menjalankan tugasnya secara baik pada unit kerja/bidang tugas masingmasing. Komitmen pegawai melahirkan rasa kecintaan, rasa tanggung jawab dan kesungguhan yang tinggi sehingga tiaptiap aparatur terdorong untuk mempersembahkan daya kerja optimal yang dimilikinya untuk kepentingan pelaksanaan tugas organisasi. Komitmen pegawai yang baik dalam bekerja diharapkan memacu tekad dan keinginan pegawai untuk melaksanakan secara baik berbagai program kerja organisasi, sehingga efektkivitas organisasi dapat terwujud sebagaimana diharapkan.

Menurut Mekta dalam (Cahyani and Sundari 2020) mendefinisikan komitmen organisasi merupakan sikap yang merefleksikan loyalitas karyawan pada 
oganisasi dan proses berkelanjutan dimana anggota organisasi mengekpresikan perhatiannya terhadap organisasi. Komitmen organisasi dapat tumbuh dari ikatan emosional terhadap perusahaan yang meliputi dukungan moral, nilai-nilai dalam perusahaan serta kemauan dalam diri untuk mengapdi pada perusahaan.

Wibowo dalam (Putri 2014) Komitmen adalah perasaan identifikasi, loyalitas dan keterlibatan yang ditunjukkan oleh pekerja terhadap organisasi atau unit organisasi.

Menurut David dalam (Pane and Fatmawati 2017) dan Agustini (2011), faktor yang mempengaruhi komitmen karyawan pada organisasi, yaitu: 1. Faktor personal: usia, jenis kelamin, tingkat pendidikan, pengalaman kerja, kepribadian. 2. Karakteristik pekerjaan: lingkup jabatan, tantangan dalam pekerjaan, konflik peran dalam pekerjaan, tingkat kesulitan dalam pekerjaan. 3. Karakteristik struktur: besar atau kecilnya organisasi, bentuk organisasi, kehadiran serikat pekerja, tingkat pengendalian yang dilakukan organisasi. 4. Pengalaman kerja: karyawan yang memiliki pengalaman kerja lebih lama dibandingkan dengan pengalaman kerja yang belum lama mempunyai tingkat komitmen yang berbeda.

Berdasarkan penelitian sebelumnya oleh (Mukhlisin, Utari, and Mardi W. 2020) menunujukan bahwa Dalam meningkatkan efektivitas kerja pegawai dapat dilakukan dengan peningkatan komitmen kerja, perubahan organisasi dan budaya organisasi di Dinas Perumahan, Kawasan Permukiman dan Ciptakarya Bojonegoro. Berdasarkan penelitian ini diketahui bahwa komitmen kerja merupakan salah satu cara untuk meningkatkan efektivitas kerja.
Selanjutnya sejalan dengan penelitian tersebut (Eldison and Widyaiswara 2020) bahwa Komitmen organisasi, perubahan organisasi, dan budaya organisasi adalah tiga hal yang dibutuhkan keefektifan pekerjaan

Indikator pengukuran variabel komitmen pegawai adalah:

1. Loyalitas/kecintaan pegawai terhadap pekerjaan

2. Tanggung jawab terhadap pekerjaan

3. Kesungguhan dalam tugas

4. Keterlibatan pegawai dalam pekerjaan.

5. Penyatuan diri pegawai terhadap organisasi.

Masalah komitmen diri pegawai dan pencapaian efektivitas organisasi Unit Pelaksana Teknis Daerah (UPTD) Pendapatan Wilayah VII Pringsewu masih merupakan hal yang problematik. Sampai saat ini masih terdapat adanya masalah dalam pelaksanaan tugas pegawai yaitu: Komitmen pegawai masih lemah, hal ini ditunjukkan dengan rendahnya loyalitas, kesungguhan serta kecintaan pegawai terhadap tugas yang dihadapi, masih ada pegawai yang mempunyai mental seorang majikan dan merasa tidak pantas untuk diperintah.

Efektivitas organisasi adalah gambaran mengenai kemampuan organisasi/lembaga dalam mencapai program kerja secara tepat waktu sesuai rencana yang ditetapkan.

Indikator pengukuran variabel efektivitas organisasi adalah:

1. Pencapaian program organisasi.

2. Kualitas/mutu kerja organisasi

3. Ketepatan waktu dalam pekerjaan

4. Prestasi pegawai dalam bekerja 
Berdasarkan uraian di atas penulis
merasa tertarik untuk melakukan
penelitian tentang: Korelasi Komitmen
Pegawai dengan Efektivitas Organisasi
di UPTD Pendapatan Wilayah VII
Pringsewu

\section{METODE PENELITIAN}

Penelitian ini bertujuan untuk mengetahui korelasi komitmen pegawai dengan efektivitas organisasi. Objek penelitian ini adalah pegawai kantor UPTD Pendapatan Wilayah VII Pringsewu. Jumlah responden dalam penelitian ini adalah sebanyak 39 orang responden.

\section{Metode Pengumpulan Data}

Metode pengumpulan data yang digunakan dalam penelitian ini adalah sebagai berikut :

1. Data primer yaitu yang dikumpulkan secara langsung dari objek penelitian yaitu pada UPTD Pendapatan Wilayah VII Pringsewu .

2. Data sekunder yaitu data yang diperoleh dari pihak lain yang telah mengolah atau mempublikasikan data primer seperti data yang diperoleh dari Literatur-literatur, Karya tulis, Karya Ilmiah, dan sebagainya.

Teknik pengumpulan data yang digunakan dalam penelitian ini adalah observasi, Kuisioner, dan dokumentasi.

Analisis data yang digunakan dalam penelitian ini menggunakan analisis kualitatif dan kuantitatif. Analisis kualitatif menggunakan rumus :

\section{$\mathbf{I}=\mathbf{N t}-\mathbf{N r} / \mathbf{n k}$}

Keterangan :

I : Interval

$\mathrm{Nt} \quad$ : Nilai/skor harapan tertinggi

$\mathrm{Nr} \quad$ : Nilai/skor harapan terendah

nk : Banyaknya kategori

Analisis Kuantitatif menggunakan uji hipotesis menggunakan rumus Product Moment Pearson yang rumusnya sebagai berikut :

$$
r_{x_{1} y}^{2}=\frac{\left\{n\left(\sum X_{1} Y\right)-\left(\sum X_{1}\right)\left(\sum Y\right)\right\}^{2}}{\left.\left\{n\left(\sum X_{1}^{2}\right)-\left(\sum X_{1}\right)^{2}\right\} n\left(\Sigma Y^{2}\right)-(\Sigma Y)^{2}\right\}}
$$

Ini digunakan untuk mengetahui korelasi antara komitmen pegawai dengan efektivitas organisasi.

\section{HASIL DAN PEMBAHASAN}

Berdasarkan penelitian di peroleh hasil sebagai berikut :

\section{Analisis Kualitatif}

Berdasarkan jawaban responden pada kuisioner tentang efektivitas organisasi ( $\mathrm{Y}$ ) yang terdiri 10 item pernyataan diperoleh hasil sebagai berikut: sebanyak $27,25 \%$ responden menjawab sangat setuju, sebanyak 55,25\% menjawab setuju, sebanyak 15,25\% menjawab kurang setuju dan sebanyak 2,25\% menjawab tidak setuju. Melihat persentase jawaban kuisioner ini, maka dapat disimpulkan bahwa secara keseluruhan efektivitas organisai di UPTD Pendapatan Wilayah VII Pringsewu sudah berjalan baik. Hal ini terlihat dari frekuensi terbesar jawaban 
responden ada di alternatif jawaban "setuju", artinya sebagian besar responden menyetujui pernyataan tersebut karena sesuai dengan kondisi yang terjadi di lokasi penelitian.

Berikut kategori jawaban responden :

Tabel 1

Kategori jawaban responden

\begin{tabular}{lcc}
\hline \multicolumn{1}{c}{ Variabel } & $\begin{array}{c}\text { Skor Rata- } \\
\text { rata }\end{array}$ & Kategori \\
\hline $\begin{array}{l}\text { Komitmen } \\
\text { Pegawai (X) }\end{array}$ & 39,58 & Setuju \\
$\begin{array}{l}\text { Efektivitas } \\
\text { Organisasi (Y) }\end{array}$ & 40.75 & Setuju \\
\hline
\end{tabular}

Dengan demikian dapat disimpulkan bahwa diinterpretasikan dengan skala interval jawaban responden berada pada kategori setuju. Artinya jawaban yang paling dominan terhadap item pernyataan kuisioner pada kedua variabel adalah jawaban setuju.

\section{Analisis Kuantitatif}

Berdasarkan penelitian bahwa hasil perhitungan tingkat keeratan hubungan antara variabel komitmen pegawai (X) dengan efektivitas organisasi (Y) yang dihitung berdasarkan koefisien korelasi adalah 0,694. Apabila diinterpretasikan dengan table pedoman koefisien korelasi, maka keeratan hubungan komitmen pegawai dengan efektivitas organisasi masuk ke Besaran tingkat keeratan hubungan antara variabel komitmen pegawai terhadap efektivitas organisasi dapat dilihat pada tabel berikut. dalam kategori tinggi, yaitu pada range 0,600 0,799 .

Tabel 2

Model Summary

\begin{tabular}{llrrr}
\hline Model & $\mathrm{R}$ & $\mathrm{R}$ Square & $\begin{array}{c}\text { Adjusted R } \\
\text { Square }\end{array}$ & $\begin{array}{c}\text { Std. Error of the } \\
\text { Estimate }\end{array}$ \\
1 & $.694^{\mathrm{a}}$ & .481 & .415 & 2.400 \\
\hline a. Predictors: (Constant), $\mathrm{X}$ & & &
\end{tabular}

Berdasarkan tabel di atas, maka dapat dilihat nilai $\mathrm{R}$ Square sebesar 0,481 , maka nilai koefisien penentu adalah $0,481 \times 100 \%$ $=48,1 \%$. Artinya variabel komitmen pegawai $(\mathrm{X})$ mampu menjelaskan perubahan variabel efektivitas organisasi (Y) sebesar $48,1 \%$, sedangkan sisanya sebesar $51,9 \%$ merupakan variasi variabel lain yang tidak diteliti.

\section{Pembahasan}

Menurut Robins (Robbin \& Judge 2015)keterlibatan pekerjaaan yang tinggi, yang berarti memihak pada pekerjaan tertentu seseorang individu, sementara 
komitmen organisasional yang tinggi berarti memihak organisasi yang merekrut individu tersebut. Pegawai yang memiliki komitmen tinggi akan menerima hampir semua tugas dan tanggungjawab pekerjaan yang diberikan padanya. Selain itu sikap juga mencakup kehangatan, afeksi, dan loyalitas terhadap organisasi merupakan evaluasi dari komitmen, serta adanya ikatan emosional dan keterikatan antara organisasi dengan pegawai. Pegawai dengan komitmen tinggi merasakan adanya loyalitas dan rasa memiliki terhadap organisasi.

Etzioni (2012:54) mengemukakan bahwa "efektivitas organisasi dapat dinyatakan sebagai tingkat keberhasilan organisasi dalam usaha untuk mencapai tujuan atau sasaran.

Dengan demikian dapat ditarik bahwa seseorang yang yang memilki komitmen dalam suatu pekerjaan akan merasa adanya loyalitas dan rasa memiliki terhadap organisasi sehingga keberhasilan untuk mencapai tujuan atau sasaran saling berhubungan. Dengan demikian bahwasannya komitmen pegawai berpengaruh terhadap efektivitas organisasi

Dalam penelitian ini tingkat korelasi antara variabel komitmen pegawai (X) dengan Variabel Efektivitas organisasi (Y) pada UPTD Pendapatan Wilayah VII Pringsewu adalah sebesar 0,694. Jika dikonsultasikan dengan tabel Interpretasi Koefesien Korelasi maka tingkat korelasi komitmen pegawai (X) dengan variabel efektivitas organisasi (Y) masuk dalam kategori korelasi "tinggi" yakni terletak pada (0,600 - 0,799). Nilai Koefisien Penentu $(\mathrm{KP})=\mathrm{R}^{2}=0,694=0,481=0,481 \times 100 \%$ $=48,1 \%$. Dapat disimpulkan bahwa variabel Komitmen pegawai (X) menjelaskan variasi perubahan variabel Efektivitas organisasi (Y) sebesar 33,4\%, sedangkan sisanya sebesar $66,6 \%$ dijelaskan oleh faktor lain yang tidak dikaji dalam penelitian ini.

Hal ini sejalan dengan penelitian oleh (Sapitri 2016) yang meneliti tentang komitmen kerja terhadap kinerja pegawai yang mendapatkan hasil diperoleh nilai $t$ hitung sebesar 6,753 dengan signifikansi 0,000 . Diperoleh nilai $\mathrm{t}$ table dengan $\mathrm{df}=\mathrm{n}-$ $\mathrm{k}-1=76-1-1=74$ pada taraf signifikansi $5 \%$ (2-tailed) sebesar 1,993. Dengan demikian diketahui $\mathrm{t}$ hitung $(6,753)>\mathrm{t}$ tabel $(1,993)$ atau signifikansi $(0,000)<5 \%(0,05)$. Dapat diartikan bahwa komitmen organisasi berpengaruh signifikan terhadap kinerja karyawan

Hasil penelitian ini mendukung penelitian terdahulu diantaranya peneltian yang dilakukan oleh (Fernanda 2015) yang menyatakan bahwa komitmen pegawai memiliki keeratan hubungan yang tinggi dengan efektivitas organisasi Berdasarkan hasil analisis mengenai Pengaruh Kinerja Pegawai Terhadap Efektivitas Organisasi di Biro Umum Bagian Humas dan Protokoler Kantor Gubernur Sumatera Utara hasil perhitungan menunjukkan bahwa harga $\mathrm{r} x \mathrm{y}$ adalah 0,42. Makna harga X (kinerja karyawan) dengan Y (efektivitas Kerja) sebesar 0,42 menunjukkan bahwa kedua variabel tersebut bervariasi secara positif. Dengan berpedoman pada koefisien korelasi dari Guilford, dapat dilihat bahwa hasil temuan $\mathrm{r} x \mathrm{xy}=0,42$ menunjukkan hubungan yang cukup berartiBerdasarkan hasil perhitungan di atas diperoleh $\mathrm{t} 0=2,87>\mathrm{t} \square$ = 2,021 maka H0 ditolak, dan Ha diterima. Dengan ditolaknya Ho dan diterimanya Ha maka dapat dikatakan bahwa ada hubungan signifikan prilaku karyawan dengan efektivitas kerja. Dari hasil koefisien korelasi determinasi di atas menunjukkan pengaruh prilaku karyawan terhadap efektivitas kerja sebesar $17,64 \%$, sedangkan $82,36 \%$ dipengaruhi oleh faktor-faktor lain. 
Begitu pula penelitian yang dilakukan oleh Tri (2017) yang menyatakan bahwa variable komitmen pegawai berhubungan erat dengan variable efektivitas organisasi dengan tingkat korelasi tinggi. Sedangkan Cahyono (2015) mengemukakan bahwa komitmen pegawai memiliki nilai tingkat korelasi yang sangat kuat dengan efektivitas organisasi.

\section{KESIMPULAN}

Berdasarkan hasil penelitian diperoleh kesimpulan sebagai berikut: Tingkat korelasi antara variabel komitmen pegawai (X) dengan Variabel Efektivitas organisasi (Y) pada UPTD Pendapatan Wilayah VII Pringsewu adalah sebesar 0,694. Jika dikonsultasikan dengan tabel Interpretasi Koefesien Korelasi maka tingkat korelasi komitmen pegawai (X) dengan variabel efektivitas organisasi (Y) masuk dalam kategori korelasi "tinggi" yakni terletak pada $(0,600$ - 0,799). Nilai Koefisien Penentu $(\mathrm{KP})=\mathrm{R} 2=0,694=0,481=0,481 \times 100 \%$ $=48,1 \%$. Dapat disimpulkan bahwa variabel Komitmen pegawai (X) menjelaskan variasi perubahan variabel Efektivitas organisasi (Y) sebesar 33,4\%, sedangkan sisanya sebesar $66,6 \%$ dijelaskan oleh faktor lain yang tidak dikaji dalam penelitian ini.

\section{DAFTAR PUSTAKA}

Cahyani, Riris anggun, and Ocky Sundari. 2020. "PENGARUH KOMITMEN ORGANISASI DAN KEPUASAN KERJA TERHADAP KINERJA KARYAWAN (Studi Pada Perusahaan Daerah Air Minum (PDAM) Kota Salatiga)." Jurnal Ekobis Dewantara V Vol 3 No.1.

Eldison, and Widyaiswara. 2020. "PENINGKATAN EFEKTIVITAS KERJA MELALUI KOMITMEN
PERUBAHAN DAN BUDAYA ORGANISASI KEMENTERIAN AGAMA KOTA PARIAMA." Jurnal Administrasi Pendidikan \& Konseling Pendidikan: JAPKP Vol 1 No 2.

Fernanda. 2015. "Pengaruh Kinerja Pegawai Terhadap Efektivitas Organisasi Di Biro Umum Bagian Humas Dan Protokoler Kantor Gubernur Sumatera Utara." Jurnal Administrasi Publik Vol. 3 No. 1. doi:

https://doi.org/10.31289/publika.v3i 1.1011 .

Mukhlisin, Woro Utari, and Nugroho Mardi W. 2020. "PENINGKATAN EFEKTIVITAS KERJA MELALUI KOMITMEN ORGANISASI, PERUBAHAN ORGANISASI DAN BUDAYA ORGANISASI DI DINAS PERUMAHAN, KAWASAN PERMUKIMAN DAN CIPTAKARYA KABUPATEN BOJONEGORO." Jurnal Mitra Manajemen 4(4):595-606. doi: 10.52160/ejmm.v4i4.375.

Noorhani, $\quad$ Muhammad. 2017. "EFEKTIVITAS ORGANISASI KELURAHAN KEMUNING KOTA BANJARBARU DALAM MENGIMPLEMENTASIKAN

PERATURAN PEMERINTAH NOMOR 96 TAHUN 2012 MENUJU PEMERINTAHAN GOOD GOVERNANCE." Jurnal Ilmiah Ekonomi Bisnis 3(3). doi: 10.35972/jieb.v3i3.143.

Pane, Sri Agustina, and Fatmawati. 2017. "PENGARUH KOMITMEN ORGANISASI TERHADAP KINERJA PEGAWAI PADA BADAN PERTANAHAN 
NASIONAL KOTA MEDAN." Jurnal Riset Manajemen \& Bisnis (JRMB) Vo. 2 No. 3.

Purnomo, Andri Joko. 2006. “ANALISIS EFEKTIVITAS ORGANISASI

DINAS PERIKANAN DAN

KELAUTAN KABUPATEN BATANG.” 3(1):31.

Putri, Fannidia Ifani. 2014. "HUBUNGAN MOTIVASI KERJA DENGAN KOMITMEN KERJA KARYAWAN DI BALAI PENDIDIKAN DAN PELATIHAN SOSIAL." 2:13.

Robbin \& Judge. 2015. Perilaku Organisasi. 16th ed. Jakarta: Selemba Empat.

Sapitri, Ranty. 2016. "PENGARUH KOMITMEN ORGANISASI TERHADAP KINERJA KARYAWAN PERUSAHAAN LISTRIK NEGARA AREA PEKANBARU." JOM FISIP 3(2):9. 